\title{
Reforma Curricular de la Educación Media y Educación Superior: Dos I nterrogantes.
}

Cristián Cox D.

Ministerio de Educación.

¿Cómo se está preparando la educación superior para responder a la reforma curricular del sistema escolar? ¿Es ésta suficientemente profunda y amplia y se implementará en forma efectiva, como para hacer pensar, a breve plazo, en alumnos con capacidades y requerimientos de nuevo tipo a las puertas de la educación terciaria del país?

La primera pregunta puede parecer prematura. La reforma curricular no ha terminado de abarcar al conjunto de los niveles del sistema escolar (lo hará recién el año 2002), y sus efectos en términos formativos no se harán sentir sino en el mediano plazo. No lo es, sin embargo, si se consideran con realismo y responsabilidad los tiempos que puede tomar en las instituciones de la educación superior, el discernimiento, discusión, diseño e implementación de los cambios demandados en la experiencia formativa que deben ofrecer a futuro, a las cohortes de egresados de una educación media reformada. Las respuestas a las dos preguntas siguientes son afirmativas, y me parece que ello constituye la base sobre la que deben pensarse hoy en día las interrelaciones de estos dos niveles del sistema educacional. En lo que sigue procuro describir brevemente la esencia de la reforma en marcha en la enseñanza media y las medidas de política educacional adoptadas para su implementación.

La principal trasformación que está afectando a la educación media es de naturaleza curricular, y consiste en una redefinición sistémica de los aprendizajes juzgados como relevantes para las vidas de los futuros egresados, sean estas de prosecución de estudios - la mayoría-, o de paso directo al mundo del trabajo. En la misma medida que la reforma curricular del sistema escolar (no solo de su nivel medio) avanza, pasando de un currículum prescrito en los documentos oficiales a un currículum implementado en las salas de clases, patios y laboratorios del sistema escolar del país, la educación superior comenzará a recibir estudiantes preparados de manera diferente que en el último cuarto de siglo.

Tal preparación diferente puede ser descrita en términos de tres ámbitos fundamentales de cambio, que afectan en forma diferenciada a la educación terciaria, tanto la universitaria como la postsecundaria de carácter técnico y profesional.

El primer cambio se refiere a la estructura curricular de los cuatro años de la educación media y distingue entre Formación General y Formación Diferenciada. Este cambio redefine la organización del currículum y la diferencia actual de las dos modalidades de educación media, al establecer una formación general de nuevo tipo en los dos primeros años, independiente del tipo de liceo - Humanista-Científico o Técnico Profesional- en que se ofrezca.

Se trata de un cambio de importancia mayor que redefine la naturaleza y extensión de la formación común que el sistema escolar se compromete a ofrecer; cambia de sentido y contenidos los dos primeros años de la educación técnico-profesional; abre opciones de diferenciación en los dos últimos años de la modalidad Humanista-Científica que no tienen precedentes en su carácter y proyecciones; y reduce drásticamente la dispersión de las opciones en el ciclo diferenciado de la modalidad Técnico-Profesional (al pasar de más de 400 especialidades a 46). 
Las especializaciones técnicas de la nueva educación técnico-profesional de nivel secundario fueron definidas en sus perfiles de competencias de salida y en los módulos formativos específicos necesarios para el logro de las mismas, en un estrecho dialogo tripartito entre representantes destacados de los mundos de la empresa, los campos académicos correspondientes y el Ministerio de Educación. Todos los CFT, así como cualquier carrera técnica de dos años, ofrecida en los tres niveles institucionales de la educación superior, debieran considerar a futuro las vinculaciones con esta nueva formación técnica de nivel secundario, que hoy en día atiende al $45 \%$ de la matrícula total de la educación media. ${ }^{1}$

Por su parte, la Formación Diferenciada en la modalidad Humanista Científica, ofrece posibilidades de profundización y expansión de conocimientos acorde a intereses y vocaciones de los alumnos, en forma más flexible y abierta que la tradicional división entre cursos científicos, matemáticos y humanistas. El marco curricular nacional define 12 horas semanales para Formación Diferenciada en 3 ㅇ y 4을 Año Medio, lo que significa que en dos o tres asignaturas, los alumnos duplicarán el tiempo de dedicación a las mismas.

El segundo cambio consiste en el establecimiento de tres áreas de objetivos y contenidos nuevos.

- Objetivos Transversales de formación intelectual y moral que deben trabajar todas las disciplinas y la cultura del liceo o colegio como un todo, referidos a :

-- crecimiento y autoafirmación personal

- desarrollo del pensamiento, formación ética

--persona y su entorno (familiar, social, laboral; ciudadanía)

- Objetivos transversales de Informática: con el propósito de proveer a todos los alumnos y alumnas de las herramientas que les permitirán manejar el 'mundo digital' y desarrollarse en él en forma competente. ${ }^{2}$

- Educación tecnológica, cuyo propósito es el desarrollo de las Habilidades y conocimientos necesarios para identificar y resolver problemas en los cuales la aplicación de tecnologías significa un aporte a la calidad de vida de las personas, así como a su comprensión del mundo tecnológico, haciéndolas consumidores críticas e informadas.

El tercer cambio afecta el qué de cada una de las áreas de conocimiento y experiencia formativa que organiza el currículum. En esta dimensión el nuevo currículum de la educación media obedece a criterios de actualización, enriquecimiento y aumento de la relevancia de las experiencias de aprendizaje que procura ofrecer. A la vez, tales criterios de base buscan responder a requerimientos formativos genéricos que las nuevas formas de producir, comunicarse y organizarse de la sociedad, plantean al sistema escolar y que apuntan al logro de:

- mayores capacidades de abstracción y elaboración de conocimientos;

- mayores capacidades de pensar en sistemas;

- mayores capacidades de experimentar y aprender a aprender;

\footnotetext{
${ }^{1}$ La matrícula total de la EM es aproximadamente de 800.000 alumnos, lo que corresponde a una cobertura de $82 \%$ del grupo 14-18 años.

${ }^{2}$ Estos objetivos tienen su base material de realización en el proyecto Enlaces y su cobertura universal de los liceos y colegios subvencionados en julio de 1999. Los laboratorios de computación presentes en todos los establecimientos secundarios subvencionados del país, tienen conexión a Internet. En agosto de 2000 el número de visitas al sitio web de Enlaces fue de 220216 - en ese mes, el sitio más visitado del país-.
} 
- mayores capacidades de comunicarse y trabajar en colaboractión;

- mayores capacidades de resolución de problemas;

- mayores capacidades de manejo de la incertidumbre y adaptación al cambio.

Lo señalado se traduce en mayores estándares de conocimiento y comprensión de las disciplinas y del mundo. El nuevo currículum plantea objetivos y contenidos, en cada disciplina, más ambiciosos que en el pasado, alineados con los estándares internacionales más exigentes, porque mayores son los requerimientos de saber y saber hacer, de los ámbitos educacionales, laborales, ciudadanos y culturales en que se desempeñarán sus egresados.

Acompaña a este nuevo currículum, en pleno proceso de implementación, inversiones públicas de cobertura universal para asegurar condiciones y medios de logro de los aprendizajes definidos por el mismo, que han transformado la base material y de acceso al conocimiento de unos contextos de aprendizaje diagnosticados a inicios de la década como pobres y anacrónicos. Estas inversiones han incluido, en la segunda mitad de los años 90:

1. infraestructura necesaria para la ampliación de la jornada escolar;

2. textos de estudio para todos los alumnos subvencionados en cinco disciplinas (lenguaje, matemática, ciencias, historia, inglés);

3. bibliotecas para cada establecimiento;

4. y, como se refirió, laboratorios de computación en cada establecimiento subvencionado, conectados en red y con acceso a Internet. La evidencia provista por evaluaciones de distinto tipo (muestrales y censales) y la evolución de indicadores convencionales sobre flujos, muestran que el proceso de cambio en marcha ha afectado contextos y relaciones de aprendizaje en forma significativa; a la vez, su impacto sobre logros de aprendizaje, siendo positivo, es aún tenue. Unos y otros mantienen fuertes marcas de inequidad en su distribución social.

¿En qué consisten los nuevos requerimientos formativos que se plantean a una educación superior ampliamente expandida y diversificada en la última década, y llena de tensiones por la revolución informática y de las comunicaciones y su corolario de nuevos perfiles de salida de sus alumnos? ¿Cómo responder a tales nuevos requerimientos? La reforma curricular del sistema de educación media es un dato de importancia fundamental en los procesos de reflexión, discusión y diseño de respuestas a estas interrogantes. 